\title{
A physics-based probabilistic forecasting methodology for hazardous microseismicity associated with longwall coal mining
}

\author{
Wenzhuo Cao $^{a *}$, Sevket Durucan ${ }^{a}$, Wu Cai ${ }^{a, b}$, Ji-Quan Shi ${ }^{a}$, Anna Korre ${ }^{a}$ \\ ${ }^{a}$ Department of Earth Science and Engineering, Royal School of Mines, Imperial College London, \\ London, SW7 2AZ, United Kingdom \\ ${ }^{b}$ State Key Laboratory of Coal Resources and Safe Mining, China University of Mining and \\ Technology, Xuzhou, Jiangsu 221116, China \\ (* indicates the corresponding author)
}

\begin{abstract}
Mining-induced microseismicity is widely considered as a result of slippage of pre-existing critically stressed fractures caused by stress perturbations around an advancing face. An in-depth analysis of the recorded microseismicity associated with longwall top coal caving mining at Coal Mine Velenje in Slovenia has been previously carried out and reported by the authors. It has been concluded that while microseismic event rate is affected by mining intensity (longwall face daily advance rate) as well as local abundance of pre-existing fractures, spatial and magnitude characteristics of microseismicity are predominantly influenced by the latter. Based upon this improved understanding of fracture-slip seismic-generation mechanism, the current work aimed at establishing a data-driven yet physics-based probabilistic forecasting methodology for hazardous microseismicity using microseismic monitoring data with concurrent face advance records. Through performing statistical analyses and probability distribution fitting for temporal, magnitude and spatial characteristics of microseismicity within a time window, a short-term forecasting model is developed to estimate the probability of potentially hazardous microseismicity over the next time interval in the form of a joint probability. The real time forecasting of hazardous microseismicity during longwall coal mining is realised through regularly updating the statistical model using the most recent microseismic sequence datasets and face advance records. This forecasting methodology is featured by the physical basis which provides a good explicability of forecasting results, and the probabilistic perspective which accounts for the stochastic nature of mining-induced microseismicity. This model has been employed to make time-varying forecasts of hazardous microseismicity around two longwall panels over a one-year coal production period at Coal Mine Velenje, and satisfactory results at both panels were achieved. In addition, the analysis suggested that the energy magnitude distribution of microseismicity is a dominant factor in contributing to the potential of hazardous microseismicity. This statistical model using microseismic monitoring data has important implications in the evaluation of mining-induced hazards and optimal control of longwall face advance in burst-prone deep-level mining sites.
\end{abstract}

Keywords: hazardous microseismicity; seismic hazard assessment; probabilistic forecasting method; fracture attributes; longwall top coal caving mining 


\section{Introduction}

Underground coal mining in Europe and worldwide is extending to deeper levels, facing an increasing potential for rock burst and coal and gas outburst hazards. Rock bursts and gas outbursts present a large threat to the safety of mine staff and facilities, as well as the stability of the mine openings (Ma et al., 2018; Mazaira and Konicek, 2015; Shepherd et al., 1981). Once such underground mining hazards occur or monitoring indicators reach the warning threshold, the mine is evacuated, and the mining production completely ceases, which significantly interferes with the mining exploitation schedule and affects production (Jackson, 1984; Wang et al., 2016).

Early warning of rock bursts and gas outbursts remains an impending challenge in mining engineering. It is of urgent need in mining practices to realise short-term forecasting (in a time range of one day) to provide a warning for the potential for rock bursts and coal and gas outbursts, as well as to allow sufficient time for the workers to withdraw from the areas that may be under threat.

The microseismic monitoring technique has been used as an effective passive seismological monitoring tool to identify regions prone to seismic hazards in the field (Ge, 2005; Hasegawa et al., 1989; Li et al., 2007). Microseismic monitoring prevails over conventional monitoring methods such as stress and displacement measurements in that it can reflect the geomechanical response of natural fractures in the rock mass, even at some distance away from the working face (Gibowicz and Kijko, 1994). Therefore, the microseismic event datasets have the potential to be used as precursors to the occurrence of rock burst and outburst hazards, as well as early warning of high gas pressure and concentration.

Initially, the anomalous increase in seismic activity prior to mining hazards, sometimes followed by returning to low levels, was utilised as a predictor for rock bursts (Brady, 1977; Trenczek and Kozłowski, 2019; Xu et al., 2016), outbursts (Styles et al., 1988), and roof failure (Iannacchione et al., 2004; Shen et al., 2008; Yu et al., 2017). Local predictions were also made when frequency of noises within the coal reached a high frequency (Hargraves, 1980). Styles (1993) noticed harmonic, monophasic tremors with emergent onsets to be precursors to abnormal gas emissions and coal and gas outbursts. Later on, extensive seismic risk assessment was performed through recognition of regularity patterns indicative of rock bursts, which are usually characterised by anomalous variations in microseismic precursors. Those microseismic precursors could be categorised as temporally-related (the number of large events, the number of events in a given period, the ratio of the number of events of different energy, the variance of event counts at two successive time moments, the change in seismic event number, etc.) (Brady, 1977; Iannacchione et al., 2004; Marcak, 1993), energy-related (sudden change of apparent volume, seismic stress drop, seismic energy release, seismic moment, energy index, energy ratio, the deviation of seismicity from the long-term trend, $b$ value, etc.) (Eneva, 1998; Gibowicz and Kijko, 1994; Ma et al., 2018; Marcak, 1993; Stewart and Spottiswoode, 1993; Trenczek and Kozłowski, 2019), and spatially-related (fractal dimension, median distance between microseismic pairs, concentration of microseismic events, etc.) (Feng et al., 2016; Ma et al., 2018; Mortimer, 1997; Stewart and Spottiswoode, 1993; Xu et al., 2016; Yu et al., 2017). Iannacchione et al. (2004) identified a consistent trend of microseismic activity (over 10-20 events per day) and relatively high convergence rates of roof (over $2.5 \mathrm{~mm}$ per day) as indicators for unstable roof failure in an underground limestone mine. Bischoff et al. (2010) related characteristic microseismic events, which represent source fault areas, with the failure of sandstone layers in the hanging and foot wall of active longwall panels in the Ruhr area, Germany. Xu et al. (2016) reported the use of concentration of microseismic events as a spatial precursor to forecast the location of strainbursts which appeared in a few days' period during hard rock tunnelling, with a success rate of $63 \%$ in a total of 2,240 forecasts. Yu et al. (2017) correlated the spatial distribution and density contours of microseismic events with the fracturing of overburden during longwall top coal caving mining. Trenczek and Kozłowski (2019) analysed the seismic energy released in microseismic monitoring, in integration with records of methane and carbon monoxide concentrations, to investigate the causes of a rock burst in a Polish mine. However, individual seismic index tends to identify different subsets of potentially-damaging events when applied in isolation, and 
the most effective seismic index may vary from site to site. In this sense, comprehensive evaluation models comprising of multiple weighted microseismic indices were further applied for rock burst risk evaluation (Cai et al., 2018, 2014).

Since the 1990s, some comprehensive quantitative methods have been introduced to the forecasting of rock bursts and gas outbursts (Eneva, 1998; Gibowicz and Kijko, 1994; Holub, 2007; Leśniak and Isakow, 2009). These methods include analysis of a combination of seismic indicators (Lu et al., 2013; Srinivasan et al., 1999, 1997), integrated spatial-time-energy analysis (Si et al., 2020; Trifu et al., 1997), spatial and temporal clustering analysis (Kijko et al., 1993; Leśniak and Isakow, 2009), probabilistic evaluation methods (Kijko et al., 1993; Lasocki, 1993; Wesseloo, 2018), comprehensive evaluation models (Cai et al., 2018, 2014), numerical modelling methods (Abdul-Wahed et al., 2006; Cao et al., 2018; Fujii et al., 1997; Sainoki et al., 2019), etc. Lasocki (1993) developed a statistical prediction method based on the mining induced seismicity data for a period of time. Kijko et al. (1993) identified clusters of microseismicity which may lead to a strong event based on a space and time metric, and further used a probabilistic method to analyse the time occurrence of microseismicity. Based on data from regional seismological monitoring, Melnikov et al. (1996) used mathematical and physical modelling to determine stress and strain precursors to rock bursts. Srinivasan et al. (1997) found it sufficient to predict mining-induced seismicity and rock bursts by linear extrapolation based on a deterministic model. Their model correlates mining with seismological parameters, using parametric pairs such as excavated tonnage and released seismic energy, number of rock bursts and released seismic energy, and number of rock bursts and number of seismic events. Fuji et al. (1997) verified the possibility to apply elastic numerical stress analysis in predicting rock bursts in deep longwall coal mining. They suggested that, by examining the maximum shear seismic moment release rate, fracturing at the work face could be successfully predicted even without the help of microseismic monitoring. Trifu et al. (1997) carried out both spatial and temporal analysis of microseismicity to estimate seismic hazards in underground mines. Srinivasan et al. (1999) identified three reliable short-term precursors for rock bursts, i.e., the rate of change of seismic event number, seismic energy release and predominant seismic signal frequency, based on microseismic monitoring data of major rock bursts in a gold mine in southern India. Feng et al. (2015) developed the probability distribution functional relationships between rock bursts and a group of microseismicity parameters, based on which a rock burst warning formula could be used to analyse the real-time microseismic data for early warning of strain bursts and fault-slip bursts. Si et al. (2020) used a combination of parameterised spatial, temporal and energy information of microseismicity to forecast the onset time and location of large seismic events in a Chinese coal mine. The combination of rock burst databases and statistical seismicity parameters facilitates early risk assessment of mining hazards.

One common drawback of the current rock burst and gas outburst assessment and mitigation methods referred to above is that their applications are mostly based on site-specific field experience, as opposed to sound physical foundations. However, forecasting success at one specific mine cannot necessarily guarantee success at other rock burst-prone mining sites. In addition, mining activities are causes of microseismicity, but most forecasting methods focus only on the microseismic monitoring data itself, without incorporating the concurrent mining intensity. This can sometimes lead to unreliable forecasting results, where the risk potential around a longwall face essentially varies with the scheduled mining intensity (ranging from complete cessation to full capacity production), while the same risk potential would be estimated based solely on previous microseismic datasets.

This paper first briefly presents the monitoring and analysis of longwall top coal caving (LTCC) mininginduced microseismicity at Coal Mine Velenje. The analysis suggested that microseismic characteristics are under the combined effects of attributes of fractures and mining intensity (Cao et al., 2020). On this basis, a physics-based, yet data-driven methodology was developed to forecast mining seismicity hazards. The physical nature of the methodology originates from characteristics of pre-existing natural fractures throughout the coal seam, which dominate the resulting microseismic patterns. A similar 
physics-based hypothesis has recently been employed to forecast the maximum magnitude of fluid injection-induced microseismicity by Afshari Moein et al. (2018). In addition, mining intensity, which plays a significant role in affecting event counts frequency, is considered by coupling real time processing of the microseismic sequence data with mining exploitation schedule in this work. The physical base of the model allows to compare respective contributions of different influencing factors to the hazard potential, and to determine the dominant factor.

\section{Monitoring of multiple-panel LTCC mining induced microseismicity at Coal Mine Velenje}

The field site for the microseismic monitoring campaign is operated by Coal Mine Velenje in Slovenia. The mine currently produces around 3.4 million tonnes of lignite per annum from two operating LTCC faces at any one time. The lens shaped lignite seam is at a depth of $200-500 \mathrm{~m}$ and has a thickness of up to $165 \mathrm{~m}$. The geological setting of the coal deposit and lithotypes have been detailed in Markič and Sachsenhofer (2010). Due to extreme seam thickness, depth and prevailing geotechnical conditions, the mining method used at Coal Mine Velenje is a combination of multi-level mining and longwall top coal caving. The entire coal deposit is divided into multiple 10 to $20 \mathrm{~m}$ thick mining levels from the top to the bottom. At each level, the lower part of the panel, ranging from 3 to 4 metres high, is cut by a shearer, while the upper section is allowed to cave and be recovered in front of the power supports (Si et al., 2015a).

An in-depth analysis of the recorded microseismicity associated with longwall top coal caving mining at Coal Mine Velenje has been recently carried out and reported (Cao et al., 2020). The microseismic monitoring campaign earmarked nine LTCC panels operating at $-80 \mathrm{~m}$ and $-95 \mathrm{~m}$ production levels during the monitoring period between February 2016 and June 2019. Longwall panels K.-80/B, K.80/C, K.-80/D, K.-80/E, and CD2 were scheduled to mine during 2016-18 with longwall panels K.95/A, K.-95/E, K.-95/D and CD3G coming into production during 2018-19 as the $-80 \mathrm{~m}$ level is being mined-out.

The seismic monitoring system installed consisted of triaxial and uniaxial seismic sensors. The triaxial seismic sensors remained in the main/permanent roadways throughout the whole monitoring period, whereas the uniaxial sensors, mostly located at the gateroads, were moved progressively as the faceline advanced or when a panel is mined-out and a new longwall panel started production. In the same manner, the seismic sensors were gradually moved to active panels at $-95 \mathrm{~m}$ level as mining at $-80 \mathrm{~m}$ level is completed (Figure 1).

Coal production at the closest working face-line to induced microseismicity was regarded as the primary source of stress perturbations, while the influence of stress redistribution caused by adjacent panels and tailgate roadways was considered as secondary and neglected in this work. To correlate mining activities and microseismicity, each microseismic event recorded was classified to be associated with the operating longwall panel that triggered it, based on the occurrence time and location of the event, and the production schedule and prevailing face-line positions of the nine longwall coal panels. The daily face advance at each LTCC panel was also recorded to establish an understanding of the influence of mining activities on various microseismic characteristics.

Figure 2 presents an example of evolution of microseismic characteristics in conjunction with the face advance rate around a representative panel K.-80/B on daily and weekly bases. In Figure 2(a), the daily seismic event count (top panel) closely follows the daily face advance (bottom panel), with lower values at weekends and holidays. In comparison, the magnitude and spatial characteristics of microseismicity, represented by seismic energy level (second panel) and distance to the active panel face-line (third panel) respectively, remained relatively consistent throughout, with the exception of fluctuation due to reduced event numbers at weekends and holidays. This suggests that the face advance rate had much less impact on the magnitude and spatial distribution of microseismicity. Rather, it is believed that the magnitude 
and spatial distribution of microseismicity are controlled by the attributes of natural fractures in the coal seam (Cao et al., 2020).

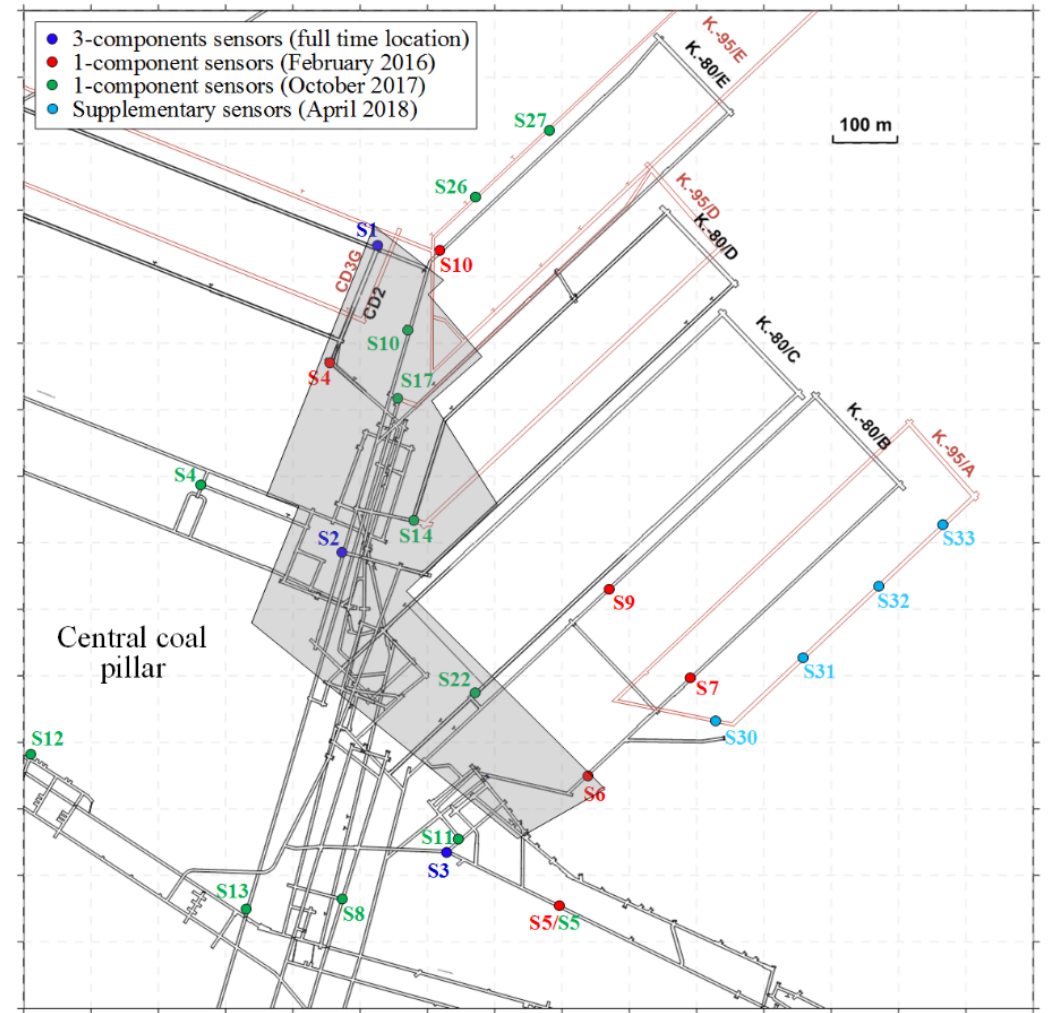

Figure 1. Mine layout at -80 and $-95 \mathrm{~m}$ production levels and the distribution of seismic stations of the microseismic monitoring system at Coal Mine Velenje during 2016-2019. The grey zone indicates the approximate shape of a central coal pillar protecting the main mine infrastructure in the production district.

To minimise deviations caused by insufficient seismic event count, Figure 2(b) presents the seismic frequency-magnitude distribution for weekly-grouped microseismicity in terms of the $b$ value (top panel) in the Gutenberg-Richter law (Richter, 1958) and the box-and-whisker diagram (middle panel). The $b$ value represents the relative abundance of small microseismic events with respect to large ones, i.e., a small $b$ value represents a large proportion of large microseismic events, and vice versa. As shown in the figure, the $b$ value showed a negative correlation with the average seismic energy, but the variation of weekly face advance rate (bottom panel) did not have apparent effects on either the $b$ value or the average seismic energy.

It has been elaborated from the analysis above that mine production as a trigger of microseismicity governs neither the location of microseismicity nor the magnitude and scaling of the energy release. Nevertheless, by considering mining-induced microseismicity as slippage of fractures throughout the coal seam triggered by mining excavation, it is believed that spatial and length attributes of underlying pre-existing fractures dominate spatial and magnitude distribution of the resulting microseismicity (Cao et al., 2020, 2018). This improved understanding of the fracture-slip seismic-generation mechanism lays the physical foundation for the probabilistic forecasting model presented in the following section. 

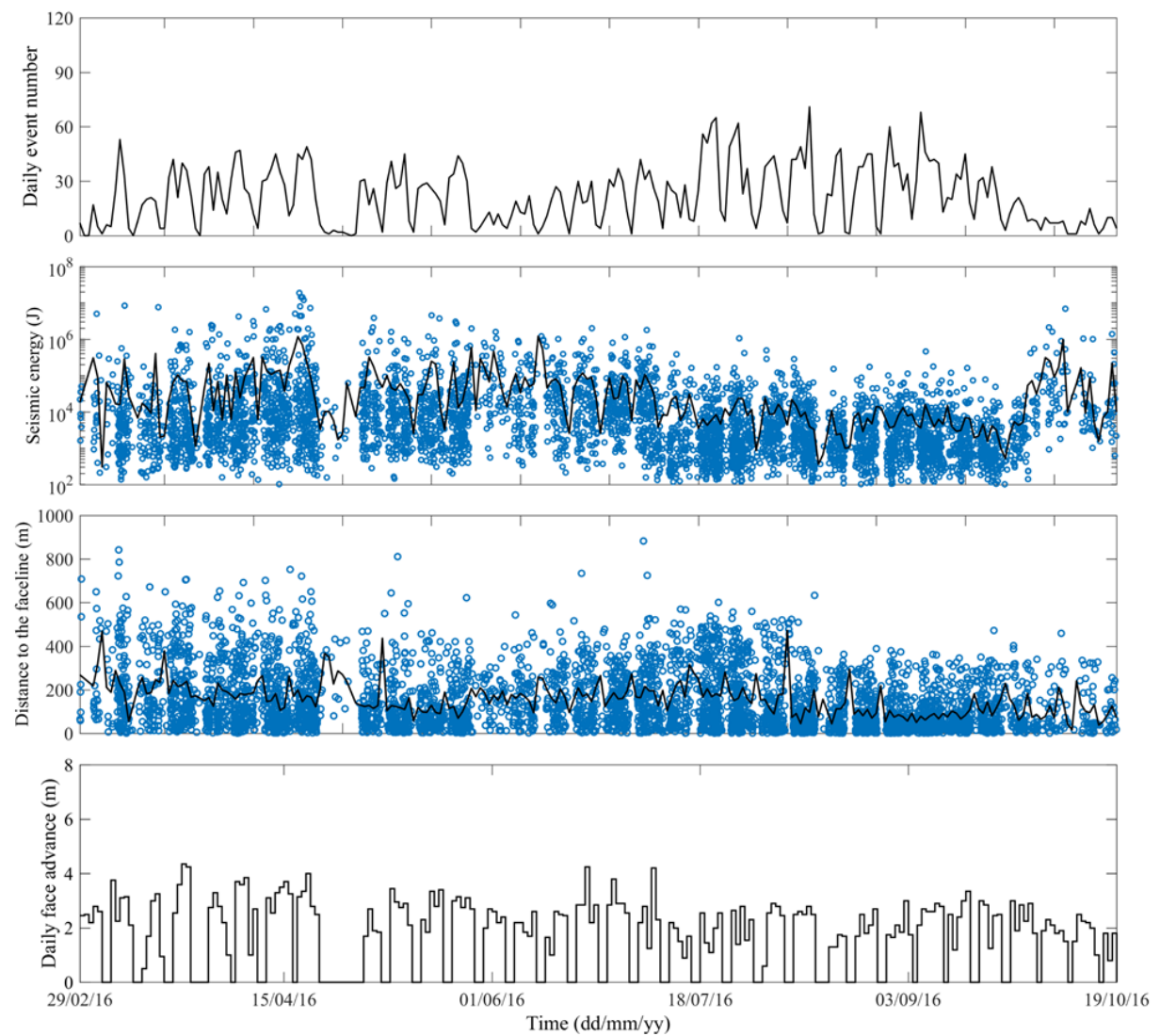

(a)
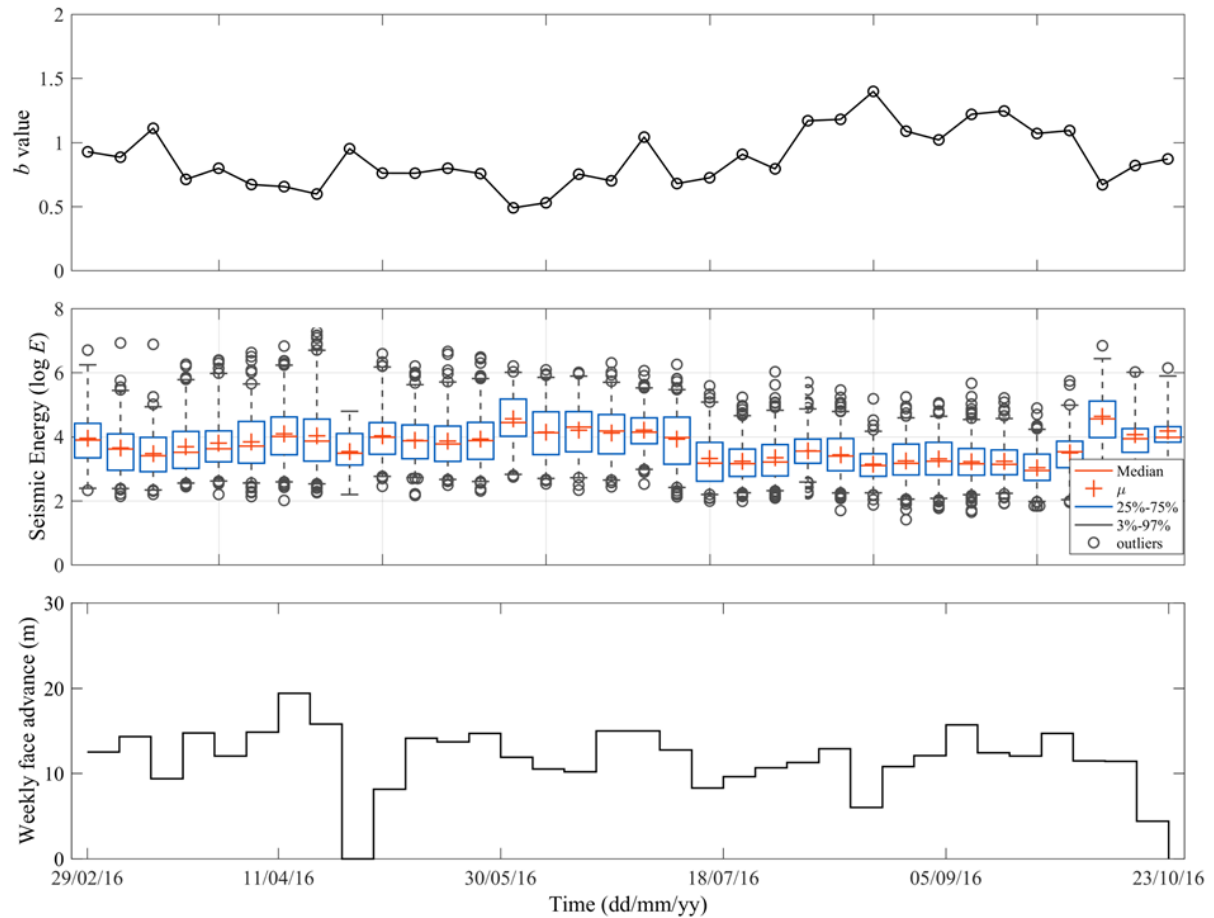

(b)

Figure 2. Evolution of characteristics of LTCC mining-induced microseismicity around panel E.-80/B: (a) on a daily basis, and (b) on a weekly basis. 


\section{A probabilistic model to forecast hazardous microseismicity associated with longwall coal mining}

Microseismic characteristics are influenced by combined effects of intrinsic factors (geological conditions represented by abundance, size and scaling of fractures, etc.), and extrinsic factors (generated stress regimes, mining methods and mining intensity, etc.). When extrinsic factors are reduced or eliminated by maintaining the same mining conditions, recorded microseismicity, or the fractures that have already slipped as a subset of neighbouring fractures, reflect the attributes of the neighbouring fracture field in a statistical manner.

It has been widely agreed that discrete natural fractures, as the source of mining-induced microseismicity, are heterogeneously distributed throughout the coal seam and surrounding rock strata. Although discrete fractures are independent of each other, they are characterised by spatial continuity in terms of attributes, i.e., two regions close to each other are likely to have similar attributes (e.g., the density, size, scaling of nature fractures, etc.) than those that are far apart (Journel and Huijbregts, 1978). As such, the spatial continuity in geology would result in the segmental stationarity of microseismic characteristics, where statistical features of microseismicity occurring within a short space of time are relatively steady (Lasocki, 1993). On the other hand, anomalous variations in mining-induced microseismicity reflect variations in corresponding attributes of the fracture field, which are indicative of stress or geological heterogeneity and give pre-warnings for the increased hazard potential (Cao et al., 2019).

Microseismic events that are either of a large magnitude or within a short distance to working faces are indicative of large potential for rock burst and gas outburst hazards in coal mines. In this work, hazardous microseismicity is defined as those resulting in large energy release and taking place close to working faces or roadways, which are the most threatening to mine workers and mining equipment. The real time forecasting of hazardous microseismicity, in this context, becomes the problem of estimating the time-varying possibility that at least one large fracture slips in the vicinity of a coal production or development face over a certain period of time, given the local fracture field and production schedule (Figure 3). Therefore, the probabilistic forecasting methodology presented in this work aims at resolving this problem by continuous evaluation of microseismic features representing characteristics of the local fracture field and mining intensity.

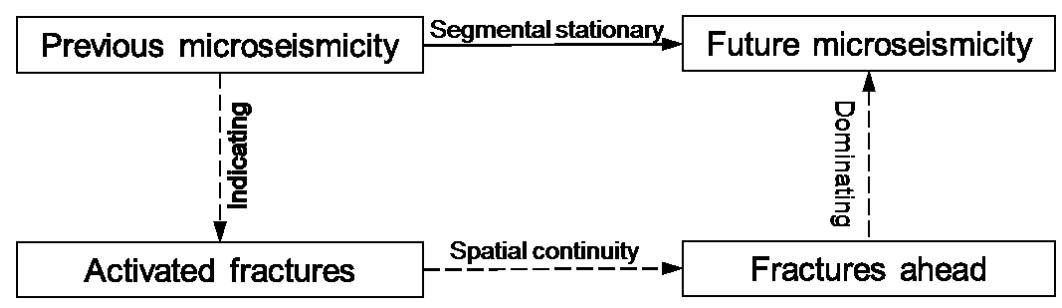

Figure 3. Schematic diagram illustrating the physical basis of the probabilistic forecasting method for hazardous microseismicity.

As the first step in the probabilistic forecasting method, the sequence of longwall face advance and associated microseismicity are recorded as inputs. Considering that geological conditions (fracture attributes in particular) and production schedule (represented by the face advance rate) are panel specific, the methodology is applied to microseismicity associated with mining at each individual LTCC panel. The assessment of recorded sequence of microseismicity around a certain longwall panel involves filtering the most recent events using a moving time window of $\Delta T$, assessing microseismic characteristics in a statistical manner, and using the fitted microseismic parameters as a basis for 
forecasting microseismicity that would occur over the next time interval $\Delta t$. This process is updated at the time interval $\Delta t$ until the completion of the LTCC panel. The procedure to forecast the potential for hazardous seismicity at time $t$ for the next time interval $[t, t+\Delta t]$ using microseismicity recorded in the time window $[t-\Delta T, t]$ involves the following steps.

The fitting of distribution and parameter estimation are first conducted for a suite of relevant characteristics such as event counts frequency, energy magnitude distribution and spatial distribution of mining-induced microseismicity within the time window. The statistical description of microseismic characteristics are described in Section 3.1, and parameter estimation for each statistical distribution is presented in Section 3.2.

Next, estimation of probability of hazardous events is performed based on the fitted statistical models of temporal, spatial and magnitude characteristics of microseismicity over the same time window. The probability of hazardous events is regarded as the joint probability considering the aforementioned characteristics. In particular, the probabilistic forecasting model of event counts frequency incorporates the impact of the current face advance rate. The estimation of probability of hazardous events is presented in Section 3.3. A flow chart of the forecasting methodology developed is presented in Figure 4.

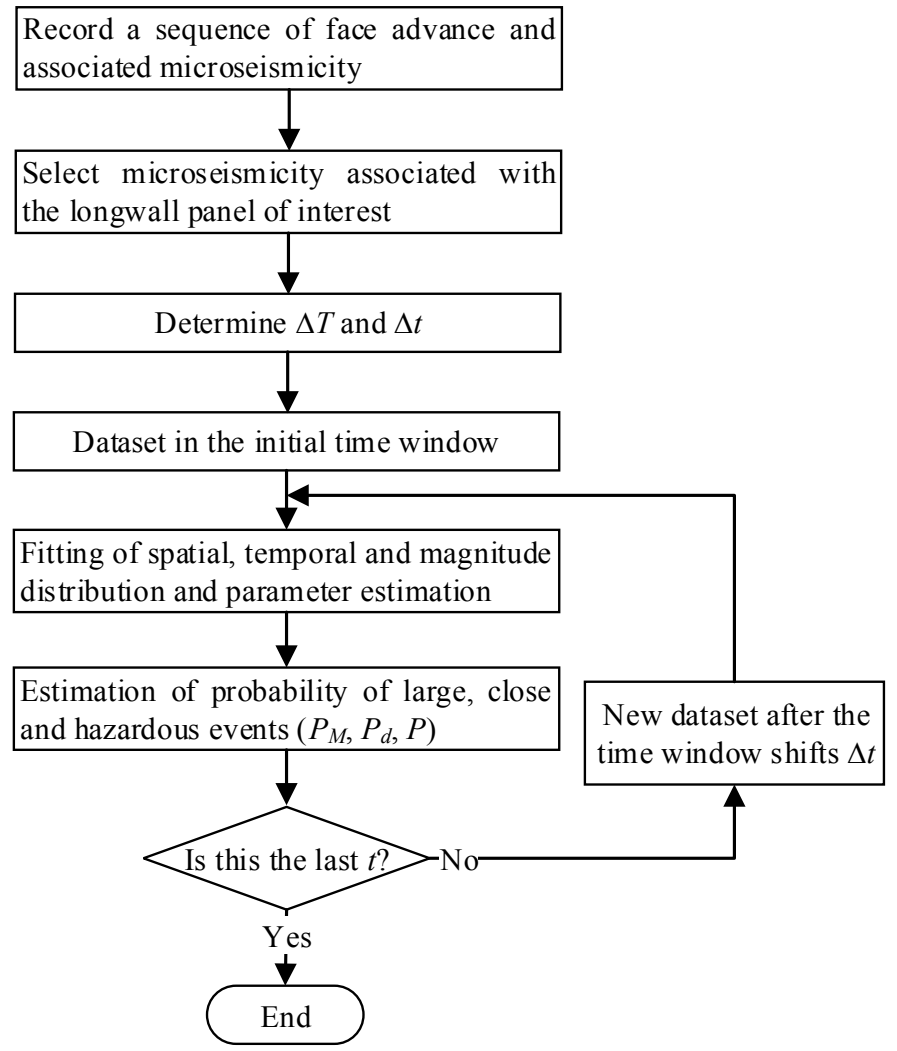

Figure 4. Flow chart of the forecasting procedure using longwall mining-induced microseismic sequence datasets with concurrent face advance records around a LTCC panel.

\subsection{Spatial, temporal and magnitude distribution}

\subsubsection{Event counts frequency}

Event counts is defined as the number of microseismic events occurring over a time interval of $\Delta t$. Given a constant face advance rate, the generation of microseismicity can be approximately considered 
as a Poisson point process, which is described by the Poisson distribution (Kagan, 2010; Kijko et al., 1993; Lasocki, 1993). The probability distribution function (PDF) for $n$ microseismic events taking place over a time interval of $\Delta t$ from time $t$ is a discrete probability distribution given by (Kagan, 2010):

$$
p(n)=\frac{[\lambda(t) \Delta t]^{n} e^{-\lambda(t) \Delta t}}{n !}
$$

where $\lambda(t)$ is the average event counts per unit time at time $t$. The evolution of $\lambda(t)$ reflects the varying abundance, or the local heterogeneity of fractures around the mining-disturbed region. Figure 5 presents examples of the monitored and fitted event counts frequency of microseismicity around three LTCC panels at Coal Mine Velenje. Due to the wide dispersion of the daily event counts, they are presented in groups with a bin interval of 10. It can be seen that the Poisson distribution gives a good fit to the frequency of daily microseismic event counts around each panel.

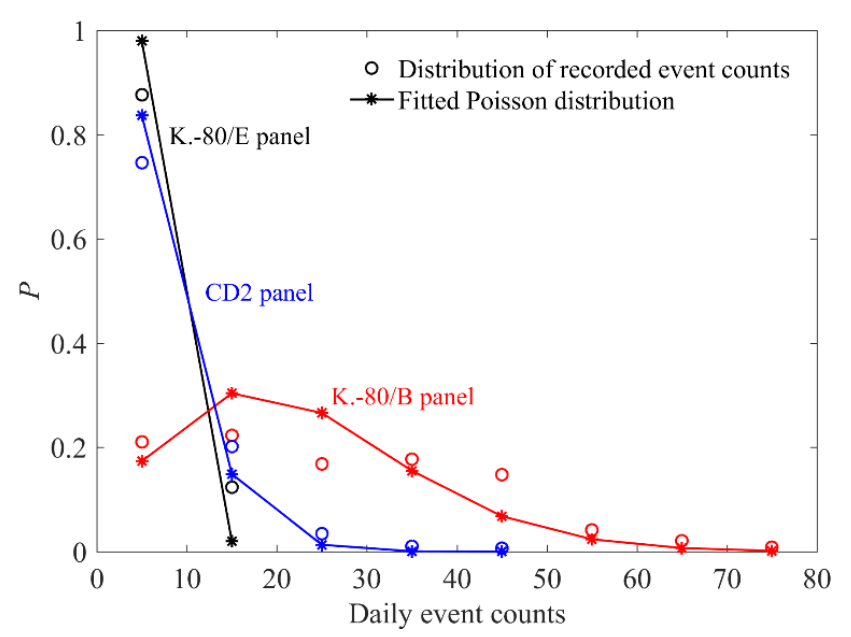

Figure 5. Frequency of daily microseismic event counts associated with longwall coal mining at three LTCC panels at the $-80 \mathrm{~m}$ level at Coal Mine Velenje (the connecting lines are only for guiding the eye).

Equation (1) can be used to forecast the frequency of daily event counts to be induced under the same mining conditions (represented by the face advance rate). Since mining operation is a dynamic process, the ever-varying face advance rate should be accounted for in forecasting event counts. Based upon the analysis from Section 2, the face advance rate has a positive correlation with the number of recorded microseismicity, owing to the physical nature that the area of mining-disturbed region is linearly correlated with the number of slipped fractures for a relatively homogeneous fracture field. Therefore, a ratio $\eta$, defined as the face advance rate $r$ during the next time interval over the average rate $\bar{r}$ during the previous monitoring period, should be used as a tuning coefficient in estimating the event counts frequency:

$$
\eta=r / \bar{r}
$$

The modified PDF can be used to estimate the frequency of microseismic event counts over the next time interval $\Delta t$ by fitting microseismic data within the time window of $\Delta T$ :

$$
p(n)=\frac{[\eta \lambda(t) \Delta t]^{n} e^{-\eta \lambda(t) \Delta t}}{n !}
$$

The most probable seismic event count over the next time interval $\Delta t$ is forecasted as $\eta \lambda(t)$. 


\subsubsection{Energy magnitude distribution}

As the previous work by the authors (Cao et al., 2019, 2018) suggests, the magnitude distribution of microseismic energy released is dominated by the size and scaling of slipped fractures. The frequencymagnitude distribution of microseismicity follows the Gutenberg-Richter law (Richter, 1958):

$$
N(>E)=a E^{-b}
$$

where $N$ is the cumulative number of seismic events with energy released greater than $E$, and $a$ and $b$ are constants.

Equation (4) can be rewritten in log-log coordinates as:

$$
\log _{10} N(>M)=\log _{10} a-b M
$$

where $M=\log _{10} E$.

Considering that there is a minimum energy magnitude $M_{\min }$ for field microseismic monitoring data due to the limited energy detection range of the geophones, the aforementioned relationship can be rearranged in the following form:

$$
\log _{10} N=\log _{10} a-b\left(M-M_{\text {min }}\right)
$$

The cumulative distribution function (CDF) of the frequency-magnitude relationship takes the form of exponential distribution (Lasocki, 1993):

$$
F(M)=1-\left(E_{\min } / E\right)^{b(t)} \quad\left(M \geq M_{\min }\right)
$$

where $b(t)$ is a constant at time $t$.

It was found that the Weibull distribution achieves a better fit than exponential distribution to empirical distribution of logarithmical seismic energy (Kijko et al., 1993; Lasocki, 1993). The PDF and CDF of the Weibull distribution are given by (Kijko et al., 1993):

$$
\begin{gathered}
f(M)=\frac{k_{\mathrm{e}}(t)}{l_{\mathrm{e}}(t)}\left[\frac{M-M_{\min }}{l_{\mathrm{e}}(t)}\right]^{k_{\mathrm{e}}(t)-1} \exp \left[-\left(\frac{M-M_{\min }}{l_{\mathrm{e}}(t)}\right)^{k_{\mathrm{e}}(t)}\right] \quad\left(M \geq M_{\min }\right) \\
F(M)=1-\exp \left[-\left(\frac{M-M_{\min }}{l_{\mathrm{e}}(t)}\right)^{k_{\mathrm{e}}(t)}\right] \quad\left(M \geq M_{\text {min }}\right)
\end{gathered}
$$

where $k_{\mathrm{e}}(t)$ and $l_{\mathrm{e}}(t)$ are shape and scale parameters at time $t$, respectively.

The CDF of the energy magnitude distribution can be fitted using microseismic data within the time window of $\Delta T$ to estimate the probability of a microseismic event with energy greater than the threshold set over the next time interval $\Delta t$. Figure 6 presents examples of the frequency-magnitude distribution and fitted Weibull distribution for field microseismic monitoring data at Coal Mine Velenje (the minimum detectable energy is around $10^{2} \mathrm{~J}$ so $M_{\min }=2$ ). 


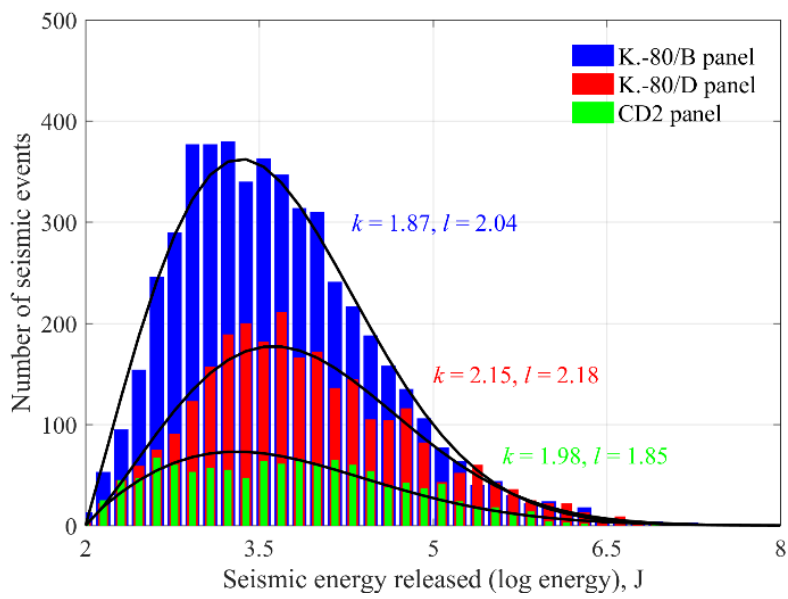

(a)

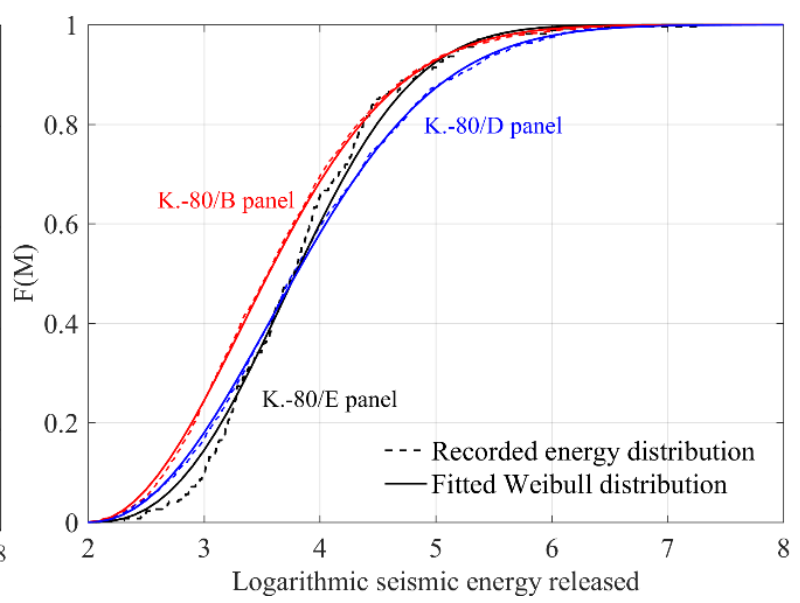

(b)

Figure 6. Examples of recorded and fitted energy magnitude distribution for mining-induced microseismic events around different LTCC panels at Coal Mine Velenje: (a) histograms, and (b) cumulative distribution.

\subsubsection{Distance to the face-line position}

The location of microseismicity reflects the spatial distribution of pre-existing natural fractures to a large extent. Given the same mining and stress conditions, the spatial clustering of microseismicity is attributed to the heterogeneous distribution of fractures. In this work, the distance of microseismicity to the face-line (i.e., the distance of the event to the closest point at the face-line when the seismic event occurs) is introduced to represent the spatial distribution of underlying natural fractures. Spatial clustering of a group of microseismic events can be characterised by a tall and thin histogram of distances to the face-line, while relatively homogeneous distribution of microseismicity yields a squat and fat histogram. Since microseismicity tends to cluster at fracture-intense regions, the average distance of microseismicity to the face-line dynamically changes with the advancing longwall face. A decrease in the average distance of microseismicity to the face-line suggests a higher chance of microseismicity occurring close to the longwall face as the mine production progresses, while an increase indicates the opposite.

Similar to the microseismic energy magnitude distribution, the spatial distribution of microseismicity with respect to the face-line is a continuous probability distribution and can be described by the Weibull distribution. The CDF is written as:

$$
F(d)=1-\exp \left[-\left[d / l_{\mathrm{d}}(t)\right]^{k_{\mathrm{d}}(t)}\right]
$$

where $k_{\mathrm{d}}(t)$ and $l_{\mathrm{d}}(t)$ are shape and scale parameters at time $t$, respectively.

The CDF of the spatial distribution of microseismicity with respect to the face-line can be fitted using microseismic data within the time window of $\Delta T$ to estimate the probability of a microseismic event falling within a certain distance to the face-line over the next time interval $\Delta t$. Figure 7 presents examples of the spatial distribution with respect to the face-line and fitted Weibull distribution for field recorded microseismicity at Coal Mine Velenje. The distribution in the histograms for the three panels in Figure 7(a) is skewed, with the peak located from 40 to $200 \mathrm{~m}$ from the longwall face. The histograms suggest that microseismic events associated with coal mining at K.-80/B and K.-80/D panels are more spatially concentrated, while those at CD2 panel are much more scattered. The Weibull distribution is well-adapted to different histograms and fits the general trend well. 


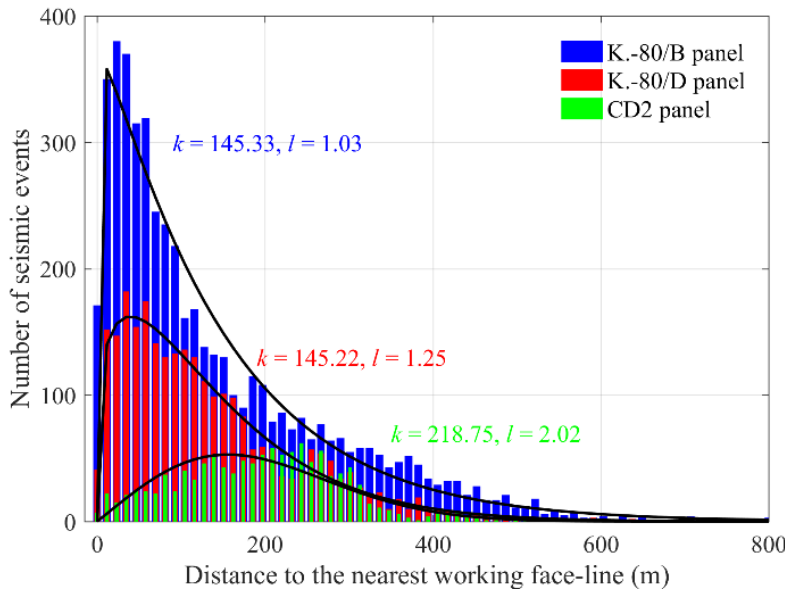

(a)

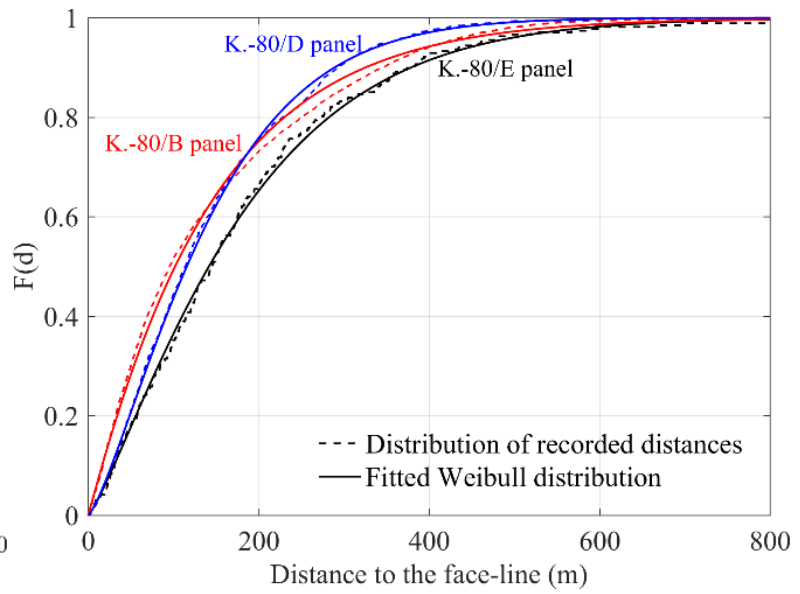

(b)

Figure 7. Examples of recorded and fitted spatial distribution with respect to the face-line for microseismic events around different LTCC panels at Coal Mine Velenje: (a) histograms, and (b) cumulative distribution.

\subsection{Parameter estimation}

Considering that the statistical models describing microseismic characteristics are known, the maximum likelihood method (Eliason, 1993) is applied to estimate relevant parameters. The method consists of calculating the maximum likelihood function, which is considered as the joint probability for sampling the set of observations. The parameters are estimated by maximising the likelihood function of the known distribution, given a sample of observations. This method can be applied for fitting either observations such as seismic event counts to discrete probability distributions, or observations such as energy magnitude distribution and spatial distribution to continuous probability distributions.

The logarithmic maximum likelihood function for seismic event counts is the sum of the logarithmic probability for each individual observation:

$$
L\left(\lambda \mid n_{1}, n_{2}, \ldots, n_{m}\right)=\sum_{i=1}^{m} \ln \left[p\left(n_{i} \mid \lambda\right)\right]
$$

where $m$ is the number of time intervals within the time window, $n_{1}, n_{2}, \ldots, n_{m}$ are seismic event counts over each time interval $\Delta t$ in the time window, and $p\left(n_{i} \mid \lambda\right)$ is the probability that $n_{i}$ seismic events take place within a time interval $\Delta t$.

The average seismic event count $\lambda$ could be estimated by solving the equation:

$$
\frac{\partial L\left(\lambda \mid n_{1}, n_{2}, \ldots, n_{m}\right)}{\partial \lambda}=0
$$

The logarithmic maximum likelihood function for the energy magnitude distribution is given by:

$$
L\left(k_{\mathrm{e}}, l_{\mathrm{e}} \mid M_{1}, M_{2}, \ldots, M_{n}\right)=\sum_{i=1}^{n} \ln \left[f\left(M_{i} \mid k_{\mathrm{e}}, l_{\mathrm{e}}\right)\right]
$$

where $n$ is the seismic event counts, and $f\left(M_{i} \mid k_{\mathrm{e}}, l_{\mathrm{e}}\right)$ is the probability that a seismic event has a magnitude of $M_{i}$.

Both shape and scale parameters $k_{\mathrm{e}}$ and $l_{\mathrm{e}}$ need to be estimated from the set of recorded seismic magnitudes, so the partial derivatives of the likelihood function with respect to each parameter are taken to form a system of equations: 


$$
\left\{\begin{array}{l}
\frac{\partial L\left(k_{\mathrm{e}}, l_{\mathrm{e}} \mid M_{1}, M_{2}, \ldots, M_{n}\right)}{\partial k_{\mathrm{e}}}=0 \\
\frac{\partial L\left(k_{\mathrm{e}}, l_{\mathrm{e}} \mid M_{1}, M_{2}, \ldots, M_{n}\right)}{\partial l_{\mathrm{e}}}=0
\end{array}\right.
$$

Likewise, the parameters for the spatial distribution of microseismicity with respect to the face-line can be estimated. The estimated parameters for the fitted distributions are considered to represent attributes of slipped fractures during $[t-\Delta T, t]$, and used to approximately represent attributes of fractures to be reactivated under the same mining conditions over the next time interval, due to the spatial continuity of geological conditions.

\subsection{Probability of hazardous events}

As suggested by previous researchers (Lasocki, 1993) and observations reported in Section 2, the spatial distribution of fractures, attributes of fractures, and mining activities can be considered as mutually independent. In particular, mining progression influences the area of extracted regions and, in turn, the number of slipped fractures per unit time, but not the size and scaling of fractures. Therefore, it is justified to estimate the probability of hazardous microseismicity as the joint probability of event occurrence, the probability of an event being a large event, and the probability of an event being close to the longwall face.

The probability that at least one event with a magnitude greater than $M$ occurs in $n$ microseismic events is written as:

$$
p_{M}=1-F(M)^{n}
$$

Considering the estimated event counts frequency from the Poisson distribution for field microseismic monitoring data over the most recent period $\Delta T$, the probability that at least one event with a magnitude greater than $M$ occurs over the next time interval $\Delta t$ is:

$$
P_{M}=\sum_{n} p(n)\left[1-F(M)^{n}\right]
$$

Likewise, the probability that at least one event with a distance less than $d$ to the face-line occurs over the next time interval $\Delta t$ is written as:

$$
P_{d}=\sum_{n} p(n)\left[1-(1-F(d))^{n}\right]
$$

In this work, a hazardous event is defined as a microseismic event with released energy greater than $M$ and falling within a distance of $d$ to the face-line. The probability of an individual seismic event being a hazardous event is the joint probability considering both the spatial and magnitude distributions:

$$
p=[1-F(M)] F(d)
$$

The probability that at least one hazardous event occurs over the next time interval $\Delta t$ is:

$$
P=\sum_{n} p(n)\left[1-(1-p)^{n}\right]
$$

Given a threshold for the probability of hazardous microseismicity, the inverse calculation of face advance can be achieved by combining equations (3) and (19).

\section{Application of the forecasting methodology at Coal Mine Velenje}

The microseismic monitoring system installed at Coal Mine Velenje recorded over 20,000 events over the monitoring period, when coal production at nine LTCC panels was underway in a sequence. The 
forecasting methodology developed was applied to recorded microseismicity associated with longwall coal mining at each of two representative completed LTCC panels (panels K.-80/B and K.-80/D), which were considered to have a complete record of mining-induced microseismicity and consist of a relatively large number of events ( $>2,500$ events each).

The length of time window $\Delta T$ needs to be determined based on the event rate and mining schedule. Segmental stationarity needs to be achieved for microseismicity within this interval to give a reliable estimation of parameters. In this sense, the interval should be sufficiently long to allow for mininginduced stress adjustment and re-equilibrium. As a reference, the time needed for microseismicity to fade out after face abandonment or to achieve normal levels of seismicity after vacation periods was found to be around 1 week, according to the observations reported in Section 2 and literature (Styles et al., 1988). On the other hand, the time window should be constrained in length in order not to compromise the capability to reflect local variability of mining conditions and indicate anomalous variations in seismic activities in time. Based on reported field observations (McKavanagh and Enever, 1980; Styles et al., 1988), the time between the first notice of anomalous changes in microseismicity patterns and visible macroscopic failure or even rock bursts and outbursts span over a wide range from 10 minutes, several hours, several days, to up to 17 days. As such, a $\Delta T$ of 14 days was used in this work, which covers microseismicity recorded over the last 10 working days. During holidays when coal extraction was halted for a longer time, $\Delta T$ was extended to cover the last 10 working days to avoid the unfavourable impact of scarcity in recorded microseismicity. The forecasted probability of hazardous microseismic events was updated on a daily basis $(\Delta t=1$ day) as a reference in order for a timely evaluation of the hazard potential.

Due to the local clustering of fracture distribution, it could be postulated that, for the same time window, microseismic events which have occurred more recently are more important. Lasocki (1993) used a temporal exponential weighting metric which assigns larger weights to those events which took place close to the next day in time. To account for the spatial clustering, a space and time weighting metric was used which is a spatial distance weighted by the product of a time constant and the time difference between the occurrence of events (Kijko et al., 1993; Liu et al., 2018). Since it is rather difficult to accurately determine the weighting metric, all the microseismic events in the same time window were assigned the same weights in this work.

Following the procedure described in Section 3, the probability of hazardous microseismicity was updated for each day from 14 days after the start of coal production until abandonment for each panel.

\section{Results and analysis}

Figure 8 presents three examples of temporal, magnitude and spatial distributions of recorded microseismicity within the time window associated with longwall mining around K.-80/D panel. These microseismic characteristics within each time window manifest segmental stationary. The distributions proposed could still describe characteristics of microseismicity within the moving time window, with good fitting performances achieved for microseismicity around each panel. As can be seen from the figure, microseismic characteristics within time windows 23/03-06/04/2016 and 05/07-18/07/2016 are similar, but the average daily event count increases, and both energy magnitude distribution and spatial distribution with respect to the face-line shift to the lower end during the time window 02/09-15/09/2016, indicating the variation of local fracture attributes around K.-80/D panel. 


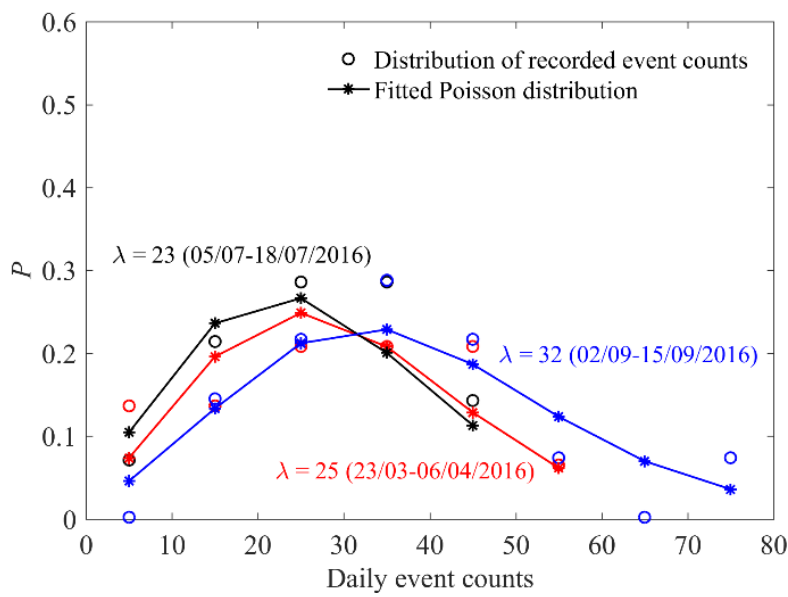

(a)

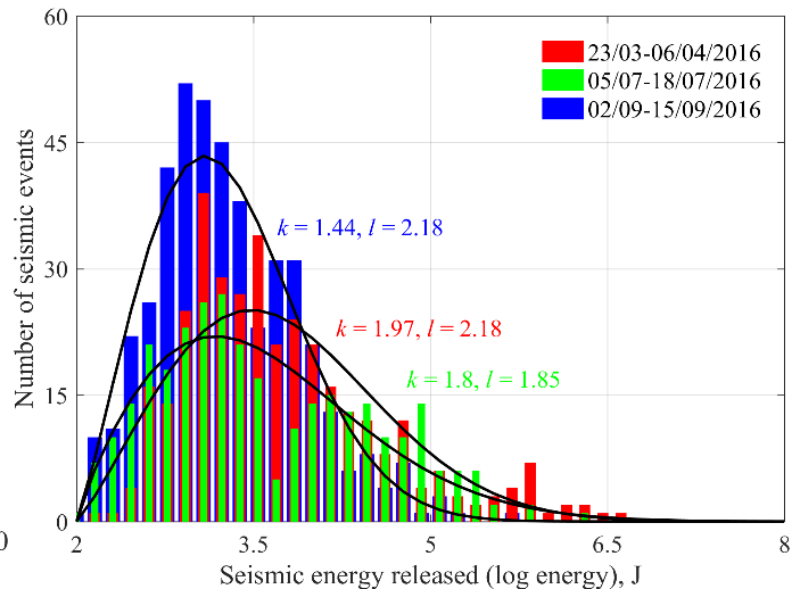

(b)

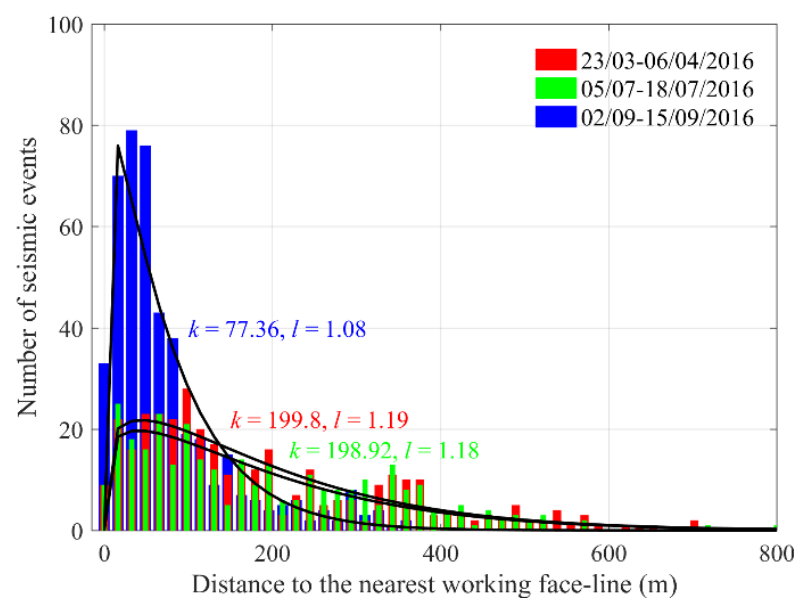

(c)

Figure 8. Temporal, magnitude and spatial distributions of field monitored microseismicity within the time window around K.-80/D panel: (a) daily event counts frequency (the connecting lines are only for guiding the eye), (b) energy magnitude distribution, and (c) spatial distribution with respect to the nearest longwall face in operation.

It is noted that, although fitted magnitude and spatial distribution of recorded microseismicity represent those of fractures, the daily microseismic event count needs to be disentangled from the impact of mining intensity to reveal the abundance of fractures around the longwall panel. To do so, the average daily event count within the time window was scaled by assuming that the longwall panel is mined at a constant face advance rate. The face advance rate ratio used is the average face advance rate within the time window over the average face advance rate during the period of mining operations (i.e., the total face advance divided by the period of mining operations), for the corresponding LTCC panel, which was also validated in discussion with the mine.

Figure 9 and Figure 10 present the time-varying scaled daily event count, the probability of a single microseismic event being a large event, and the probability of a single microseismic event being close to the face-line, based on fitted distributions for microseismicity within the moving time window around the two longwall panels. In these figures, the scaled daily event number under the average face advance rate represents the density of underlying fractures, the probability of a single microseismic event being a large event reflects the size distribution of underlying fractures, and the probability of a single microseismic event being close to the longwall face reveals the spatial distribution of underlying fractures. These figures represent the dynamic evolution of abundance, magnitude and spatial distribution of fractures around the panels as longwall faces advance. The curves are fairly continuous, 
which verifies that attributes of fractures around longwall panels reflected from the recorded microseismicity are spatially continuous.

Although the two longwall panels are close to each other, their fracture attributes manifest different features. The abundance of local fractures around K.-80/B panel remains fairly steady in the first four months of coal production, stays at a heightened level between 18/07-15/10/2016, and decreases below the normal level afterwards. The abundance of fractures around K. $-80 / \mathrm{D}$ panel is also steady in the first three months of coal production, but then gradually increases around fivefold by the completion of the panel. These trends also indicate that as the two longwall faces moved towards the central coal pillar, the increasing level of stress concentration had an overall favourable effect on the abundance of underlying pre-existing fractures. The fracture size distribution is mostly stable for both longwall panels, with reduced risks of large events in some periods, such as 18/07-15/10/2016 for K.-80/B panel and 30/08-15/10/2016 for K.-80/D panel.
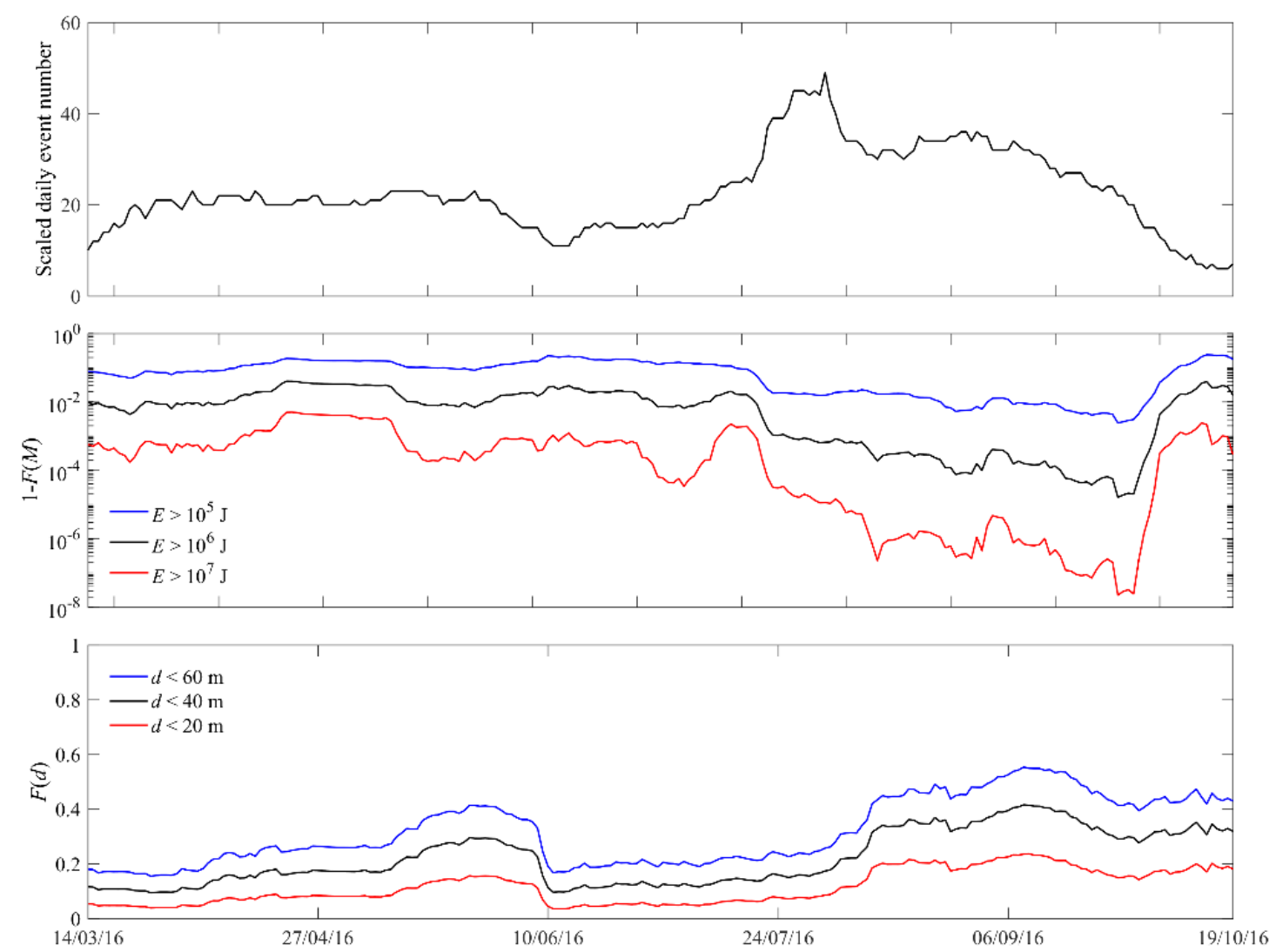

Figure 9. Time-varying temporal, magnitude and spatial seismic indicators decoupled from mining activities for microseismicity around panel K.-80/B. 

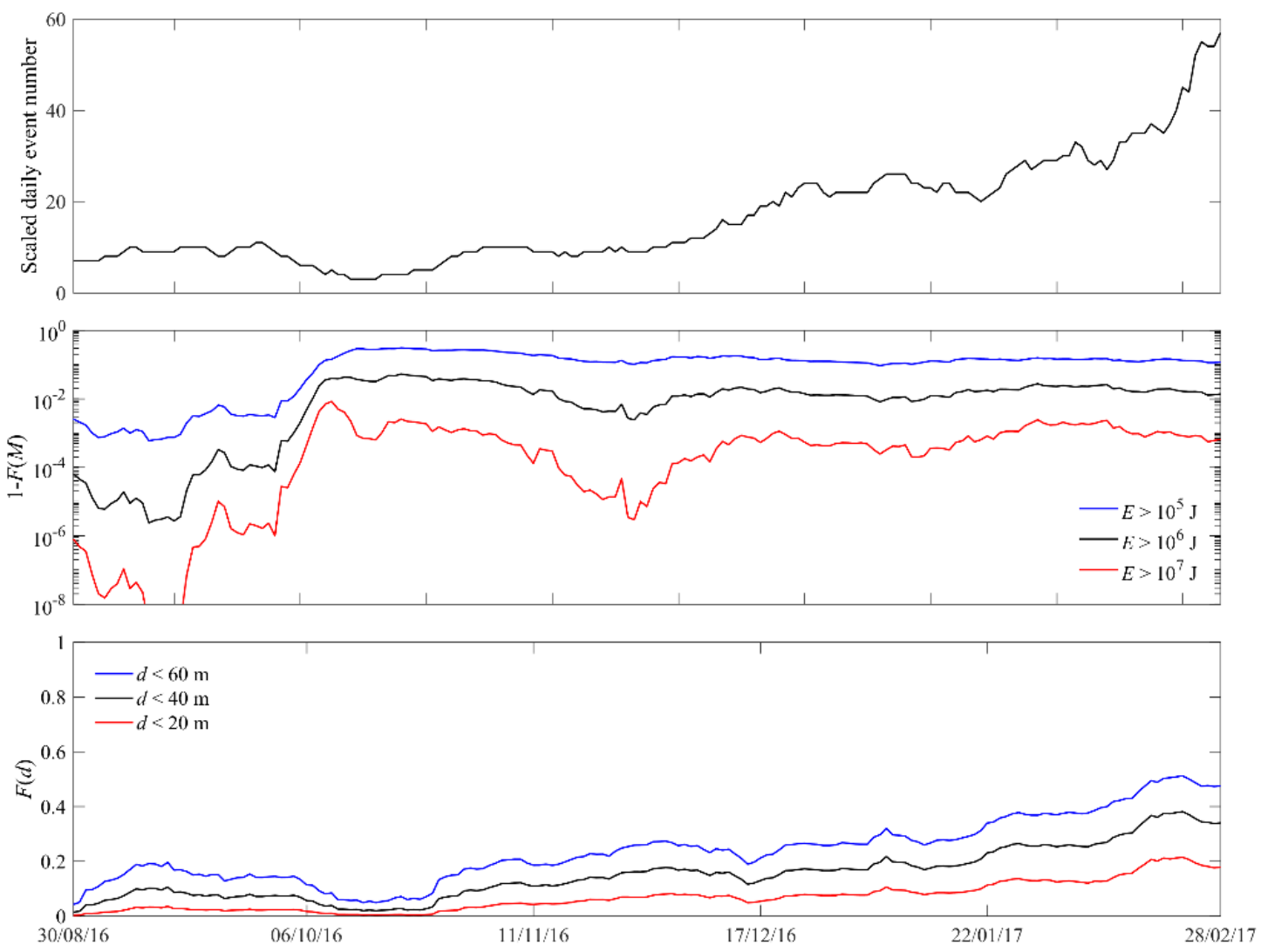

Figure 10. Time-varying temporal, magnitude and spatial seismic indicators decoupled from mining activities for microseismicity around panel K.-80/D.

It is interesting to note that the probability of a single microseismic event being close to the face-line shows a general increasing trend for each of the two panels during coal production, which results from the shift of a squat and fat to a tall and thin distribution of the distance to the face-line (Figure 8 (c)). This change indicates elevated levels of spatial clustering of fractures, since both longwall faces were advancing towards the central coal pillar with high stress concentration. Therefore, time-varying seismic indicators decoupled from mining activities have reflected the influence of local stress concentration at the central coal pillar on both the abundance and spatial distribution of microseismicity, and thus can be used to forecast future seismicity at the same area.

Figure 11 and Figure 12 present the time-varying forecasted daily event number, and probability that large microseismicity, microseismicity close to the working face, and potentially hazardous microseismicity occur on the day of forecasting for the two LTCC panels. Recorded daily numbers of total microseismic events, large events, events close to the working face, and hazardous events are plotted respectively for validation.

The forecasted daily event counts from the statistical model show excellent agreement with recorded numbers of microseismicity, with large event counts being forecasted at high face advance rates, and no events being forecasted when the coal production ceases.

The forecasted probability of large microseismicity $P_{\mathrm{M}}$, which was estimated according to Equations (3) and (16), approximately follows the general trend of $1-F(M)$ in Figure 9 and Figure 10. The face advance rate on the day of forecasting affects the forecasted probability by tuning the forecasted event counts. When the coal production ceases at weekends or during holidays, the probability of large microseismicity is forecasted as 0 since the forecasted event count is 0 . By comparison to $b$ values analysis for weekly microseismicity around panel K.-80/B in Figure 2, the evolution of $P_{\mathrm{M}}$ and $b$ values 
display distinctly opposite trends, which verifies that the decrease in the $b$ value indicates an increase in the large event risk. The forecasted probability for microseismicity with an energy released greater than $10^{5} \mathrm{~J}$ mostly stays at a high level above $70 \%$ on working days for both longwall panels, and it can be seen that these events are quite common. By contrast, the forecasted probabilities for microseismicity at energy levels of $10^{6}$ and $10^{7} \mathrm{~J}$ show a significant decrease of several orders of magnitude, and such events are much less frequent. As can be seen from Figure 11, when the forecasted probability of microseismicity with $E>10^{7} \mathrm{~J}$ around the K.-80/B panel reaches a peak of $6.5 \%$ and $12.9 \%$ on 19 and 20 April 2016, four such large microseismic events occurred around the same panel, two on each of those two days, respectively.
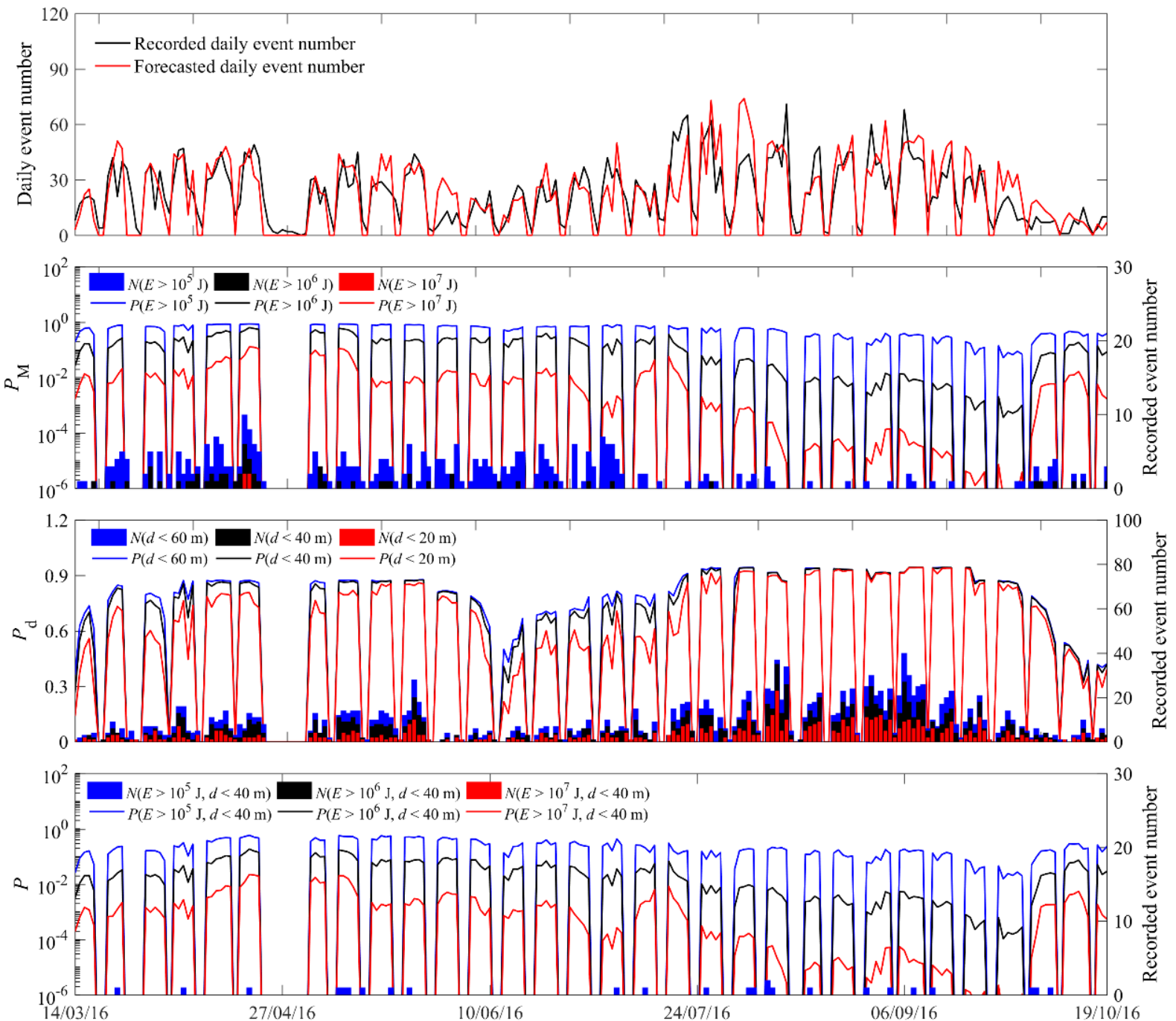

Figure 11. Time-varying forecasted daily event number, and forecasted probability that at least one large microseismic event, one microseismic event close to the face-line, and one hazardous microseismic event occurs on the day of forecasting around panel K.-80/B.

The forecasted probability of microseismicity close to the working face, which was estimated according to Equations (3) and (17), approximately follows the general trend of $F(d)$ in Figure 9 and Figure 10. This forecasted probability was also tuned by the face advance rate ratio. Considering the spatial distribution of microseismicity (Figure 7), microseismicity close to the working face are not as rare as large microseismicity. More microseismicity were recorded close to the working face when the 
statistical model estimates a higher probability of such events. As an example, the statistical model estimates the probability that at least one microseismic event occurs close to the working face to be above $90 \%$ on working days between 25/07-23/09/2016 around K.-80/B panel, and the forecasted probabilities of microseismicity with $d<60 \mathrm{~m}, d<40 \mathrm{~m}$ and $d<20 \mathrm{~m}$ have little differences. This is supported by a large number of microseismicity recorded within $20 \mathrm{~m}$ distance to the K.-80/B face during these dates (Figure 2).
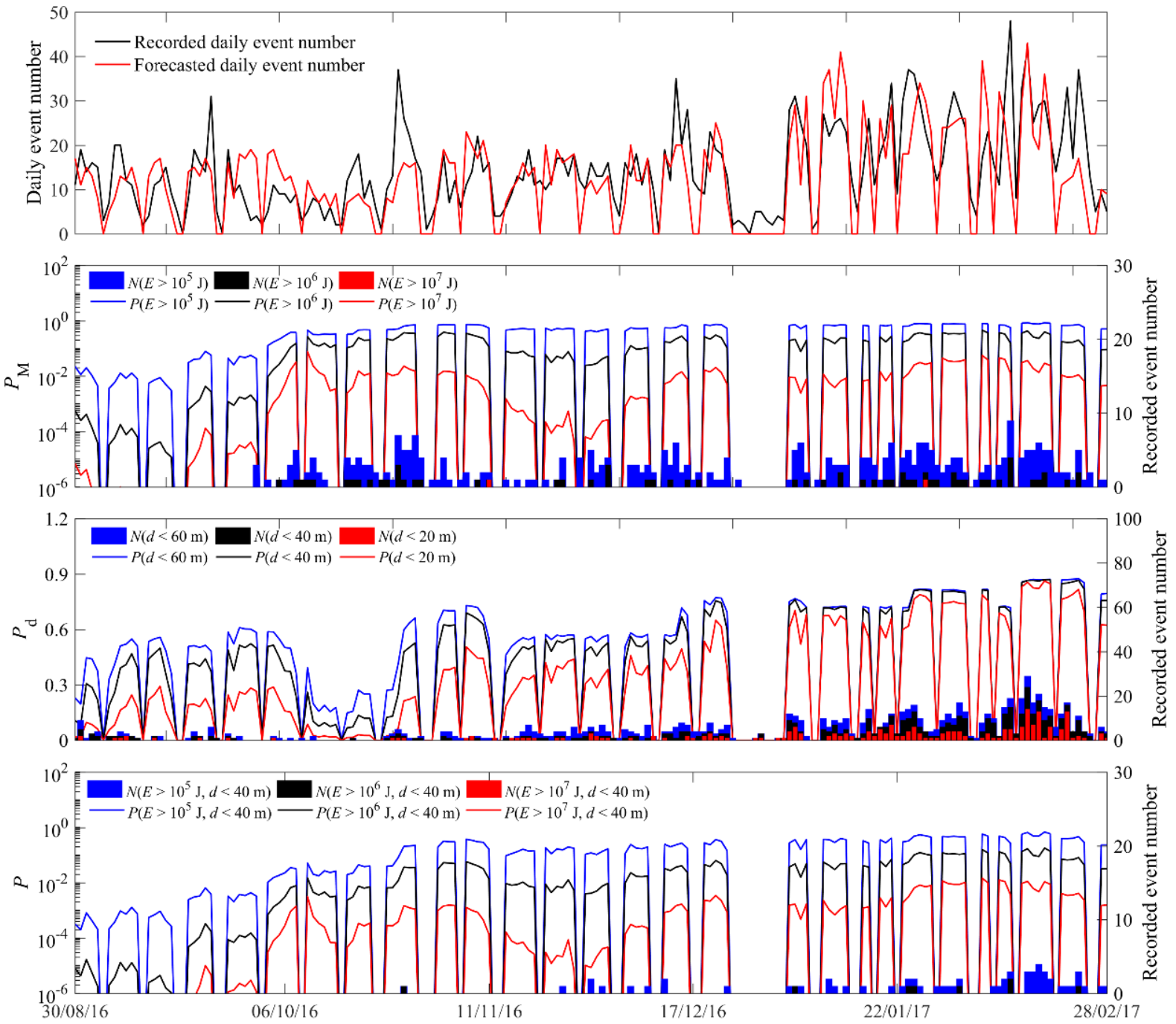

Figure 12. Time-varying forecasted daily event number, and forecasted probability that at least one large microseismic event, one microseismic event close to the face-line, and one hazardous microseismic event occurs on the day of forecasting around panel K.-80/D.

The potentially hazardous zone was taken as the area within $40 \mathrm{~m}$ of working faces at Coal Mine Velenje, as the fracturing of the mined and roof coal extended up to $40 \mathrm{~m}$ ahead of LTCC faces at the mine ( $\mathrm{Si}$ et al., 2015b). Events within $40 \mathrm{~m}$ of the working face and with seismic energy greater than $10^{5}, 10^{6}$ and $10^{7} \mathrm{~J}$ are considered as potentially hazardous microseismicity. The forecasted time-varying probability of potentially hazardous microseismicity closely follows the variation of that of large microseismicity $\left(P_{\mathrm{M}}\right)$ for the two longwall panels, which means that the forecasting result is dominated by the impact of magnitude distribution of recorded microseismicity. By contrast, the forecasted probabilities of potentially hazardous microseismicity for the two longwall panels are around one order 
of magnitude lower than those of large microseismicity with the same energy. As a result, only a few microseismicity with $E>10^{6} \mathrm{~J}$ and $d<40 \mathrm{~m}$ and no microseismicity with $E>10^{7} \mathrm{~J}$ and $d<40 \mathrm{~m}$ were recorded around these longwall panels over the coal production period.

\section{Discussion}

Microseismic monitoring as an early warning means of rock bursts and coal and gas outbursts hazards was carried out around nine longwall coal panels at Coal Mine Velenje from 2016 to 2019. Analysis of recorded microseismicity suggested that spatial and magnitude characteristics of microseismicity are dominated by those of underlying fractures, while microseismic event rate is under the combined effects of local fracture abundance and mining intensity (Cao et al., 2020). Given that fracture abundance, fracture size distribution, fracture location and mining intensity are mutually independent, their respective contribution to hazardous microseismicity can be isolated and analysed separately. Therefore, the probability that at least one hazardous microseismic event occurs over the next time interval can be estimated as the joint probability considering the event counts frequency, energy magnitude distribution and spatial distribution with respect to the longwall face.

The probabilistic forecasting methodology developed has several features that outperform many conventional forecasting and evaluation methods based on microseismic monitoring data. First, the physics basis of the forecasting methodology, i.e., the fracture-slip seismic-generation mechanism, makes forecasting results more accurate (e.g., satisfactory forecast of seismic event counts considering the mining intensity) and more explicable (e.g., correlation between the Gutenberg-Richter law and power law fracture length distribution) (Figure 11 and Figure 12). The physical basis of the method also allows the method to be universally appliable to other mine sites with different geological and mining conditions. Second, in contrast to deterministic forecasting methods (e.g., classifying a zone as hazardous or non-hazardous, forecasting a hazardous microseismicity will happen or not in a given time window) (Cai et al., 2018; Iannacchione et al., 2004; Xu et al., 2016), the probabilistic forecasting method has more robust performance by taking the stochastic nature of mining-induced microseismicity into account. Third, a distinct feature of the method is to meaningfully disentangle the influence of mining intensity and fracture attributes on characteristics of hazardous microseismicity, which provides the opportunity to evaluate the respective contribution of each influencing factor and identify the dominating factors. Fourth, the forecasting method incorporates the mining intensity effect on the risk of hazardous microseismicity, such that a recommended upper limit of mining intensity could be estimated given a probability limit for hazardous microseismicity (Cao, 2019). This provides the theoretical foundation for real-time regulation of longwall face advance rate following the forecasting results, which has significant field application value. Fifth, the forecasting method allows mine managers the flexibility to define both the magnitude and area of influence for hazardous microseismicity according to site-specific conditions and requirements, which is crucial for the widespread application of the forecasting method at different field sites.

The feasibility and efficiency of this probabilistic forecasting methodology are highly dependent on the volume and quality of source microseismicity data. To obtain reliable forecasting results based on microseismic monitoring data, possible sources of error need to be controlled in the whole process from field monitoring, pre-processing to data analysis (Ge, 2005). In field monitoring, geophones with large energy detection ranges are favourable to avoid incomplete sampling of microseismicity, and thus an incomplete representation of local fractures (Mignan and Woessner, 2012; Wiemer and Wyss, 2000). To obtain microseismic events associated with the longwall panel of interest, great efforts need to be devoted to the proper pre-processing of recorded raw data, including pickup of events, filtering out irrelevant events, and classification of events. In data analysis, an appropriate length of time window needs to be determined to ensure that the segmental stationary of microseismicity can be achieved within that time window (Lasocki, 1993). 
The proposed probabilistic model could well represent time-varying temporal, magnitude and spatial microseismic characteristics, based on which a fairly satisfactory forecasting results can be achieved. Nevertheless, it should be borne in mind that the forecasted results of large microseismicity from this probabilistic model is very sensitive to statistical variations due to small samples of large microseismicity, which originates from an intrinsic nature of microseismicity, i.e., the frequencymagnitude distribution (power law fracture size distribution in essence) (Bonnet et al., 2001; Richter, 1958). It can be seen from Figure 9 and Figure 10 that while the estimated 1-F(M) for events with $E>$ $10^{5} \mathrm{~J}$ is fairly stable over the coal production period, that for events with $E>10^{7} \mathrm{~J}$ has a larger fluctuation spanning over several orders of magnitude. This is because given the large population of not so large seismic events (at $10^{5} \mathrm{~J}$ energy level) and small population of very large ones (at $10^{7} \mathrm{~J}$ energy level), the relative abundance of the former tends to be steady over the coal production period, while that of the latter is susceptible to fluctuations in the recorded number of such events. Therefore, albeit the results obtained are statistically correct, they are susceptible to biases caused by inaccurate source data, in particular the recorded number of large microseismicity. Nevertheless, this sensitivity can be significantly reduced through the use of a low threshold for the magnitude of hazardous microseismicity considered. Therefore, using the methodology proposed, a reliable and robust forecasting performance was achieved using an appropriate threshold, not too large to be influenced by statistical variations, and not too small to overestimate the number of hazardous microseismicity.

Though the statistical method provides a probabilistic perspective to the evaluation of hazard risks, it is noteworthy that the method does not explicitly consider the impact of stress environment (Harris, 1998; Marcak and Mutke, 2013; Orlecka-Sikora et al., 2012; Shen et al., 2008) and coal properties (Cao et al., 2019), and it lacks a stress change perspective to forecast the generation of individual microseismic events (Cao et al., 2019, 2018). Thus, the inherent weakness of this method is that it could not identify the most probable location of potential hazards. To address this problem, hazardous regions should be analysed and identified using a mechanical approach by reference to the physical mechanism, which is that fracture slippage is susceptible to be triggered under critical stress states (Grasso and Sornette, 1998; Harris, 1998; Marcak and Mutke, 2013; Orlecka-Sikora et al., 2012). Nevertheless, the estimated timevarying probability of hazardous microseismicity in the vicinity of operational longwall faces provides a valuable indicator to evaluate the seismic risk and inform the coal production process, significantly contributing to the prevention of mining hazards.

\section{Conclusions}

This paper presents a physics-based yet data-driven statistical model to characterise microseismicity, which considers the event counts frequency to obey a Poisson distribution, and both energy magnitude distribution and spatial distribution with respect to the longwall face to follow a Weibull distribution. Based on the segmental stationary of microseismicity (the spatial continuity of fracture attributes in essence), the probability of potentially hazardous microseismicity could be estimated from fitted distributions of microseismic characteristics using recent microseismic sequence datasets and face advance records. On this basis, time-varying hazard risks could be evaluated by daily updating the fitted statistical model of microseismicity within a moving time window. This methodology is advantageous in that the estimated probability is given in the form of a joint probability, which allows for quantifying the respective contribution of each influencing factor.

The proposed statistical model was applied to forecast the potential for hazardous microseismicity for two longwall panels at Coal Mine Velenje. Results showed that the forecasted daily event counts are in excellent agreement with the recorded ones. The increase of forecasted probability of large microseismicity is consistent with the decrease of $b$ values for weekly microseismicity. The high forecasted probabilities for large microseismicity and microseismicity within a short distance to the face-line were verified by high recorded numbers of such events. Results suggest that the energy magnitude distribution of microseismicity plays a dominant role in the potential for hazardous 
microseismicity. This statistical model, which uses long-term microseismic monitoring data, has important implications in the evaluation of mining-induced hazards and optimal control of longwall face advance in burst-prone deep-level mining sites.

\section{Acknowledgements}

This research was carried out as part of the European Commission Research Fund for Coal and Steel (RFCS) funded project "Monitoring, Assessment, Prevention and Mitigation of Rock Burst and Gas Outburst Hazards in Coal Mines-MapROC", Grant No: RFCR-CT-2015-00005. The authors would like to express their gratitude to the research partners at Coal Mine Velenje and Central Mining Institute (GIG) for their contributions to the project. The first author acknowledges the Engineering and Physical Sciences Research Council (EPSRC) International Scholarship awarded by the Faculty of Engineering at Imperial College London. Wu Cai would like to thank the China Postgraduate Council International Postdoctoral Exchange Fellowship Program (Grant No. 20170060).

\section{References}

Abdul-Wahed, M.K., Al Heib, M., Senfaute, G., 2006. Mining-induced seismicity: Seismic measurement using multiplet approach and numerical modeling. Int. J. Coal Geol. 66(1), 137-147.

Afshari Moein, M.J., Tormann, T., Valley, B., Wiemer, S., 2018. Maximum magnitude forecast in hydraulic stimulation based on clustering and size distribution of early microseismicity. Geophys. Res. Lett. doi:10.1029/2018GL077609

Bischoff, M., Cete, A., Fritschen, R., Meier, T., 2010. Coal mining induced seismicity in the Ruhr area, Germany. Pure Appl. Geophys. 167, 63-75.

Bonnet, E., Bour, O., Odling, N.E., Davy, P., Main, I., Cowie, P., Berkowitz, B., 2001. Scaling of fracture systems in geological media. Rev. Geophys. 39, 347-383. doi:10.1029/1999RG000074

Brady, B.T., 1977. Anomalous seismicity prior to rock bursts: Implications for earthquake prediction. Stress Earth 357-374.

Cai, W., Dou, L., Li, Z., Liu, J., Gong, S., He, J., 2014. Microseismic multidimensional information identification and spatio-temporal forecasting of rock burst: a case study of Yima Yuejin coal mine, Henan, China. Chinese J. Geophys. Ed. 57, 2687-2700.

Cai, W., Dou, L., Zhang, M., Cao, W., Shi, J.Q.J.-Q., Feng, L., 2018. A fuzzy comprehensive evaluation methodology for rock burst forecasting using microseismic monitoring. Tunn. Undergr. Sp. Technol. 80, 232-245. doi:10.1016/j.tust.2018.06.029

Cao, W., 2019. Monitoring and modelling of microseismicity associated with rock burst and gas outburst hazards in coal mines. Imperial College London.

Cao, W., Durucan, S., Cai, W., Shi, J.-Q., Korre, A., Jamnikar, S., Rošer, J., Lurka, A., Siata, R., 2020. The role of mining intensity and pre-existing fracture attributes on spatial, temporal and magnitude characteristics of microseismicity in longwall coal mining. Rock Mech. Rock Eng. 53, 4139-4162.

Cao, W., Shi, J.-Q., Si, G., Durucan, S., Korre, A., 2018. Numerical modelling of microseismicity associated with longwall coal mining. Int. J. Coal Geol. 193, 30-45. doi:10.1016/j.coal.2018.04.010

Cao, W., Shi, J.Q., Durucan, S., Korre, A., Jamnikar, S., 2019. Numerical modelling of anomalous microseismicity influenced by lithological heterogeneity in longwall top coal caving mining. Int. J. Coal Geol. 216, 103305.

Eliason, S.R., 1993. Maximum likelihood estimation: Logic and practice. Sage.

Eneva, M., 1998. In search for a relationship between induced microseismicity and larger events in mines. Tectonophysics $289,91-104$. 
Feng, G.L., Feng, X.T., Chen, B. rui, Xiao, Y.X., Yu, Y., 2015. A Microseismic Method for Dynamic Warning of Rockburst Development Processes in Tunnels. Rock Mech. Rock Eng. 48, 2061-2076. doi:10.1007/s00603-014-0689-3

Feng, X.-T., Yu, Y., Feng, G.-L., Xiao, Y.-X., Chen, B., Jiang, Q., 2016. Fractal behaviour of the microseismic energy associated with immediate rockbursts in deep, hard rock tunnels. Tunn. Undergr. Sp. Technol. 51, 98-107.

Fujii, Y., Ishijima, Y., Deguchi, G., 1997. Prediction of coal face rockbursts and microseismicity in deep longwall coal mining. Int. J. Rock Mech. Min. Sci. 34, 85-96. doi:10.1016/S1365$1609(97) 80035-4$

Ge, M., 2005. Efficient mine microseismic monitoring. Int. J. Coal Geol. 64, 44-56.

Gibowicz, S.J., Kijko, A., 1994. An Introduction to Mining Seismology.

Grasso, J.-R., Sornette, D., 1998. Testing self-organized criticality by induced seismicity. J. Geophys. Res. Solid Earth 103, 29965-29987. doi:10.1029/97JB01344

Hargraves, A.J., 1980. A review of instantaneous outburst data, in: The Occurrence, Prediction and Control of Outbursts in Coal Mines. The Aust. Inst. Min. Metall., Melbourne, pp. 1-18.

Harris, R.A., 1998. Introduction to Special Section: Stress Triggers, Stress Shadows, and Implications for Seismic Hazard. J. Geophys. Res. Solid Earth 103, 24347-24358. doi:10.1029/98JB01576

Hasegawa, H.S., Wetmiller, R.J., Gendzwill, D.J., 1989. Induced seismicity in mines in Canada-an overview. pure Appl. Geophys. 129, 423-453.

Holub, K., 2007. A study of mining-induced seismicity in Czech mines with longwall coal exploitation. J. Min. Sci. 43, 32-39.

Iannacchione, A.T., Coyle, P.R., Prosser, L.J., Marshall, T.E., Litsenberger, J., 2004. The relationship of roof movement and strata-induced microseismic emissions to roof falls.

Jackson, L.J., 1984. Outbursts in coal mines. IEA Coal Res.

Journel, A., Huijbregts, C., 1978. Mining geostatistics. Academic Press, London.

Kagan, Y.Y., 2010. Statistical distributions of earthquake numbers: consequence of branching process. Geophys. J. Int. 180, 1313-1328.

Kijko, A., Funk, C.W., Brink, A.V.Z., 1993. Identification of anomalous patterns in time-dependent mine seismicity, in: In Proceedings of the 3rd International Symposium on Rockbursts and Seismicity in Mines. pp. 205-210.

Lasocki, S., 1993. Statistical short-term prediction in mining induced seismicity, in: Rockbursts and Seismicity in Mines. pp. 211-216.

Leśniak, A., Isakow, Z., 2009. Space-time clustering of seismic events and hazard assessment in the Zabrze-Bielszowice coal mine, Poland. Int. J. Rock Mech. Min. Sci. 46, 918-928.

Li, T., Cai, M.F., Cai, M., 2007. A review of mining-induced seismicity in China. Int. J. Rock Mech. Min. Sci. 44, 1149-1171.

Liu, J., Xu, S., Li, Y., Lei, G., 2018. Analysis of Rock Mass Stability Based on Mining-Induced Seismicity: A Case Study at the Hongtoushan Copper Mine in China. Rock Mech. Rock Eng. 0, 0. doi:10.1007/s00603-018-1541-y

Lu, C.-P., Dou, L.-M., Zhang, N., Xue, J.-H., Wang, X.-N., Liu, H., Zhang, J.-W., 2013. Microseismic frequency-spectrum evolutionary rule of rockburst triggered by roof fall. Int. J. Rock Mech. Min. Sci. 64, 6-16.

Ma, T., Tang, C., Tang, S., Kuang, L., Yu, Q., Kong, D., Zhu, X., 2018. Rockburst mechanism and prediction based on microseismic monitoring. Int. J. Rock Mech. Min. Sci. 110, 177-188. doi:10.1016/j.ijrmms.2018.07.016 
Marcak, H., 1993. The use of pattern recognition methods for prediction of the rockbursts, in: Proc. 3rd Int. Symp. on Rockbursts and Seismicity in Mines. pp. 223-226.

Marcak, H., Mutke, G., 2013. Seismic activation of tectonic stresses by mining. J. Seismol. 17, 11391148. doi:10.1007/s10950-013-9382-3

Markič, M., Sachsenhofer, R.F., 2010. The Velenje lignite: its petrology and genesis. Geological Survey of Slovenia, Ljubljana.

Mazaira, A., Konicek, P., 2015. Intense rockburst impacts in deep underground construction and their prevention. Can. Geotech. J. 52, 1426-1439. doi:10.1139/cgj-2014-0359

McKavanagh, B.M., Enever, J.R., 1980. Developing a microseismic outburst warning system, in: In Proceedings of the Second Conference on Acoustic Emission/Microseismic Activity in Geologic Structures and Materials. pp. 211-225.

Melnikov, N.N., Kozyrev, A.A., Panin, V.I., 1996. Induced seismicity in large-scale mining in the kola peninsula and monitoring to reveal informative precursors. Pure Appl. Geophys. PAGEOPH 147, 263-276. doi:10.1007/BF00877482

Mignan, A., Woessner, J., 2012. Estimating the magnitude of completeness for earthquake catalogs. Community Online Resour. Stat. Seism. Anal. 1-45.

Mortimer, Z., 1997. Fractal statistics for the local induced seismicity in some Polish coal mines, in: Rockbursts and Seismicity in Mines. Balkema Rotterdam, pp. 49-54.

Orlecka-Sikora, B., Lasocki, S., Lizurek, G., Rudziński, Ł., 2012. Response of seismic activity in mines to the stress changes due to mining induced strong seismic events. Int. J. Rock Mech. Min. Sci. 53, 151-158. doi:10.1016/j.jirmms.2012.05.010

Richter, C.F., 1958. Elementary Seismology. WH. Freeman and Company, San Francisco.

Sainoki, A., Mitri, H.S., Chinnasane, D., Schwartzkopff, A.K., 2019. Quantitative Energy-Based Evaluation of the Intensity of Mining-Induced Seismic Activity in a Fractured Rock Mass. Rock Mech. Rock Eng. 52, 4651-4667.

Shen, B., King, A., Guo, H., 2008. Displacement, stress and seismicity in roadway roofs during mininginduced failure. Int. J. Rock Mech. Min. Sci. 45, 672-688. doi:10.1016/j.ijrmms.2007.08.011

Shepherd, J., Rixon, L.K., Griffiths, L., 1981. Outbursts and geological structures in coal mines: A review. Int. J. Rock Mech. Min. Sci. 18, 267-283. doi:10.1016/0148-9062(81)91192-X

Si, G., Cai, W., Wang, S., Li, X., 2020. Prediction of Relatively High-Energy Seismic Events Using Spatial-Temporal Parametrisation of Mining-Induced Seismicity. Rock Mech. Rock Eng. 1-22.

Si, G., Jamnikar, S., Lazar, J., Shi, J.Q., Durucan, S., Korre, A., Zavšek, S., 2015a. Monitoring and modelling of gas dynamics in multi-level longwall top coal caving of ultra-thick coal seams, part I: Borehole measurements and a conceptual model for gas emission zones. Int. J. Coal Geol. 144145, 98-110. doi:10.1016/j.coal.2015.04.008

Si, G., Shi, J.Q., Durucan, S., Korre, A., Lazar, J., Jamnikar, S., Zavšek, S., 2015b. Monitoring and modelling of gas dynamics in multi-level longwall top coal caving of ultra-thick coal seams, Part II: Numerical modelling. Int. J. Coal Geol. 144-145, 58-70. doi:10.1016/j.coal.2015.04.009

Srinivasan, C., Arora, S.K., Benady, S., 1999. Precursory monitoring of impending rockbursts in Kolar gold mines from microseismic emissions at deeper levels. Int. J. Rock Mech. Min. Sci. 36, 941948.

Srinivasan, C., Arora, S.K., Yaji, R.K., 1997. Use of mining and seismological parameters as premonitors of rockbursts. Int. J. Rock Mech. Min. Sci. 34, 1001-1008. doi:10.1016/S13651609(97)80009-3

Stewart, R.D., Spottiswoode, S.M., 1993. A technique for determining the seismic risk in deep-level mining, in: Proc. 3rd Int. Symp. on Rockbursts and Seismicity in Mines. pp. 123-128. 
Styles, P., 1993. Implications of harmonic-tremor precursory events for the mechanism of coal and gas outbursts, in: Proc. 3rd Int. Symp. on Rockbursts and Seismicity in Mines. pp. 415-421.

Styles, P., Emsley, S.J., Jowitt, T., 1988. Microseismic monitoring for the prediction of outbursts at Cynheidre Colliery, Dyfed, S. Wales. Geol. Soc. London, Eng. Geol. Spec. Publ. 5, 423-433. doi:10.1144/GSL.ENG.1988.005.01.47

Trenczek, S., Kozłowski, A., 2019. Research and analysis of monitoring records to determine the causes of the disaster in underground mining, in: IOP Conference Series: Earth and Environmental Science. IOP Publishing, p. 12056.

Trifu, C.-I., Shumila, V., Urbancic, T.I., 1997. Space-time analysis of microseismicity and its potential for estimating seismic hazard in mines, in: Rockbursts and Seismicity in Mines. pp. 295-298.

Wang, J., Jiang, F., Meng, X., Wang, X., Zhu, S., Feng, Y., 2016. Mechanism of Rock Burst Occurrence in Specially Thick Coal Seam with Rock Parting. Rock Mech. Rock Eng. 49, 1953-1965. doi:10.1007/s00603-015-0894-8

Wesseloo, J., 2018. The spatial assessment of the current seismic hazard state for hard rock underground mines. Rock Mech. Rock Eng. 51, 1839-1862.

Wiemer, S., Wyss, M., 2000. Minimum magnitude of completeness in earthquake catalogs: Examples from Alaska, the western United States, and Japan. Bull. Seismol. Soc. Am. 90, 859-869.

Xu, N.W., Li, T.B., Dai, F., Zhang, R., Tang, C.A., Tang, L.X., 2016. Microseismic monitoring of strainburst activities in deep tunnels at the Jinping II hydropower station, China. Rock Mech. Rock Eng. 49, 981-1000.

Yu, B., Zhao, J., Xiao, H., 2017. Case Study on Overburden Fracturing during Longwall Top Coal Caving Using Microseismic Monitoring. Rock Mech. Rock Eng. 50, 507-511. doi:10.1007/s00603-016-1096-8 